\title{
REVIEW
}

\section{Fluid resuscitation in prehospital trauma care: a consensus view}

\author{
M Revell, K Porter, I Greaves
}

Emerg Med J 2002;19:494-498

This paper reviews the evidence concerning the administration of fluid to trauma victims in the prehopsital setting. Clinical evidence from a consensus meeting is used to propose a practical and safe framework for the managment of such patients.

See end of article for authors' affiliations .....................

Correspondence to: Mr K Porter, Selly Oak Hospital, Raddlebarn Road, Birmingham B29 6JD, UK: kp999uk@aol.com

Accepted for publication 14 June 2002

....................
vidence based medicine describes clinical practice in which patient care and therapeutic decisions are supported by information gained from a careful consideration of the available worldwide research literature. Ideally, unequivocal clinical conclusions should be drawn based on the results of carefully conducted studies. Unfortunately, even at the beginning of the 21 st century, in many areas this evidence is patchy or contradictory. Furthermore, a number of the most fundamental questions confronting present day clinicians may never be answered by suitably conducted studies. Initial evidence might suggest, for example, that a particular treatment offers a small survival advantage compared with another, but the number of recruits required to ensure a meaningful trial may render it impractical in terms of logistics and cost. In addition, an increasingly severe ethical framework makes it probable that many definitive clinical studies would not gain ethical approval.

In the meantime, practitioners in all disciplines have to try to base their clinical decisions on whatever sound evidence is available. Most clinicians also find it helpful to trade experiences and ideas. Although such exchanges are strictly speaking anecdotal, they often fill the gaps in our present scientific knowledge, allowing decisions to be made regarding patient care on the basis of shared experience, where firm evidence is inconclusive or absent.

It is with the aim of reconciling clinical experience and current evidence in the prehospital trauma setting that the following article has been prepared. Evidence from the scientific literature is cited where possible. The remainder is a consensus reached by experienced trauma personnel from a variety of backgrounds (Pre-hospital Fluid Resuscitation in Trauma: a consensus meeting. Faculty of Pre-hospital Care, University Hospital Birmingham, August 2000). The concept of value being added to raw data through the input of acknowledged authorities is a well established process in evidence based medicine.

These guidelines provide one simple strategy applied to the use of fluids for trauma patients in the prehospital setting. There are three main areas that are attended to; cannulation, the choice of fluid, and the quantity of fluid given. It is intended that these issues should continue to be debated and, where ideas are put forward, it is expected that they will evolve or change as experience and evidence grow together.

\section{CANNULATION \\ Issues}

Early venous access in trauma patients has traditionally been regarded as of great importance. ${ }^{23}$ It permits administration of fluids, where necessary, or other drugs such as anaesthetic, analgesic, and resuscitation agents. ${ }^{4}$ Placement of a venous line is likely to be technically easier in the early stages of shock than when hypovolaemia has progressed and compensatory mechanisms have resulted in peripheral vasoconstriction. As a consequence, paramedics have been encouraged to use such skills in trauma.

While early successful cannulation will save time when the patient arrives in hospital, ${ }^{5}$ it is also clear that repeated unsuccessful attempts or access with a cannula of insufficient gauge will hinder progress at the same stage.

Recently, interventions made by paramedics before the patient arrives in hospital have come under close scrutiny. In a retrospective study, Demetriades found that outcome was worse in a group of 4856 patients brought to hospital by paramedics than in 926 patients brought in by bystanders, relatives, and the police. ${ }^{6}$ Assuming the results are truly representative, it is has been suggested that poor outcomes relate to detrimental effects of prehospital advanced life support (ALS) measures. There is other evidence suggesting ALS methods improve survival, ${ }^{7}$ but the aggressive use of fluid, in particular, has been called into question.

Independent of the use of intravenous fluids, however, transfer time to hospital seems to be an important predictor of outcome. ${ }^{8}$ Improvements may be possible here. Cannulating ambulance crews seem to spend longer on scene and this extra time does seem to be related to the interventions they perform..$^{9-11}$ If the administration of fluid prehospital is open to question, then this apparent delay in transfer to obtain circulatory access should also come under scrutiny.

One way to balance the benefits to be gained by obtaining venous access prehospital with the risk of lengthening transfer times is to attempt cannulation en route. ${ }^{12}$ This approach has both training and Health and Safety implications, but has received strong support. ${ }^{13}{ }^{14}$

The management of entrapped patients is a special situation. ${ }^{15}$ Here again, the focus should be on keeping the time to hospital as short as possible. The coordinated roles of all the emergency 
Box 1 Factors influencing choice of fluids

- early haemodynamic effects

- effects on haemostasis

- oxygen carriage

- distribution and capillary endothelial leak

- modulation of inflammatory response

- safety

- $\mathrm{pH}$ buffering

- method of elimination

- practicality and cost

services are critical in keeping delays to a minimum. ${ }^{16}$ It is probable that efforts to cannulate in these situations will not extend the time of transfer. In addition, there are usually compelling reasons for obtaining a venous line on scene; principally the need for analgesia, but also, on occasion, for resuscitation drugs and fluids.

\section{Consensus view}

Cannulation at an early stage is desirable. However, in most situations, priority should be given to transfer of the patient to a centre where definitive care can be provided. The on scene time should not be prolonged by attempts to gain a line. Intravenous access during transit has been used successfully and should be considered where appropriate expertise and training are available. A limit of two attempts en route is reasonable.

In cases of entrapment, circulatory access should be gained on scene. This reflects the unique demands of this area of prehospital medicine.

\section{CHOICE OF FLUID FOR RESUSCITATION \\ Issues}

This area continues to be one in which, despite an increasing body of evidence, no consensus regarding choice of fluid has been reached. Broadly, the choice of options includes:

- no fluid

- crystalloids (isotonic and hypertonic)

- colloids (mainly gelatins and starch solutions)

- oxygen carrying solutions (to include blood and blood substitutes).

The decision is a complex one and includes consideration of the factors listed in box 1 .

\section{Early haemodynamic effects}

The aim of administering fluids is to restore end-organ perfusion and therefore oxygen delivery. An increase in circulating volume will have a tendency to increase cardiac output and blood pressure. The speed with which a given fluid will produce its effect will largely be determined by its volume of distribution within the body and how quickly it equilibrates. A sudden increase in blood flow may not be beneficial because it has the potential to precipitate rebleeding from sites where physiological mechanisms have brought about cessation of haemorrhage.

\section{Haemostasis}

In general, administration of fluid has a detrimental effect on haemostasis and a tendency to increase bleeding. ${ }^{17}{ }^{18}$ To begin with, primary haemostatic thrombus may be dislodged from a vessel causing rebleeding, as outlined above. Most fluids will cause vasodilatation, at least as a result of reversing hypovolaemia, with similar risks. With the obvious exception of fresh frozen plasma, most will also reduce blood viscosity and dilute clotting factors to the detriment of haemostatic mechanisms. Direct interference with the clotting cascades is seen with some starches. ${ }^{19}$ Finally, hypothermia induced coagulopathy should be avoided, if possible, and the fluids should be warmed. $^{2021}$

\section{$\mathrm{pH}$ buffering}

Acidosis results from anaerobic metabolism of energy substrate, producing lactic acid, phosphoric acids, and unoxidised amino acids. This can have negative inotropic effects and predispose to arrhythmias. Manipulating $\mathrm{pH}$ in itself, with the use of bicarbonate, for example, is not presently advised as it impairs oxygen delivery to the tissues by its effect on the dissociation of oxygen from haemoglobin. Some protein based fluids, such as albumin and fresh frozen plasma, have $\mathrm{pH}$ buffering properties, which may be beneficial. ${ }^{22}$

\section{Oxygen carriage}

High flow oxygen is administered routinely to trauma patients. ${ }^{2}$ The main thrust of fluid administration is directed towards reversing hypovolaemia. In the early stages, the relative anaemia caused by blood loss is compensated for by the decrease in blood viscosity, which permits improved peripheral oxygen delivery. Anaemia associated with haemorrhage is considered to be secondary in importance to hypovolaemia in the accumulation of oxygen debt. To date, no artificial oxygen carrying solutions have reached widespread use.

\section{Modulation of the inflammatory response and capillary}

leak

Critically ill patients exhibit increased capillary permeability that can permit molecules such as albumin and water to pass into the interstitium exacerbating oedema and impeding oxygen transfer. ${ }^{23}{ }^{24}$ Molecular size is a major determinant of whether a fluid will remain primarily in the intravascular space or be distributed more widely within the extracellular space. Both lower molecular weight synthetic colloids and exogenous albumin solutions leave the circulation to a greater or lesser degree. ${ }^{25}$ Conversely, higher molecular weight colloids, which remain in the intravascular space, exert an oncotic pull that can result in cellular dehydration. Accordingly, these should be administered with adequate amounts of water. ${ }^{27}$ Evidence suggests that high molecular weight starches may have a secondary direct down regulatory action on capillary leak via an action on endothelial surface molecules. ${ }^{28}$

\section{Safety}

The fluid of choice must be one that can be administered safely in all patient groups. Some starches and haemoglobin solutions have detrimental effects on renal function. Anaphylaxis has been seen with blood products in particular, but also with gelatins. The communication of viral and prion infections is a risk associated with blood and its derivatives. The possible consequences on a cross match sample in the later stages of treatment have also caused concern in the use of dextran, but modern dextrans are believed not to cause the same difficulties. ${ }^{29}$

\section{Practicality and cost}

The ideal resuscitation fluid should be cheap, with a long shelf life. It should be easy to store and to warm when required. Except in the rarest of circumstances, prehospital administration of blood is almost never achievable.

\section{Consensus view}

Modern perfluourocarbons and haemoglobin-b oxygen carriers are currently still largely experimental. ${ }^{30}{ }^{31}$ Blood (together with human albumin solution and fresh frozen plasma) is costly and difficult to store, having a comparatively short shelf life. In addition, issues regarding compatibility and disease transmission make blood and its derivatives unlikely candidates as a permanent solution in the prehospital situation. 
The debate as to the superiority of crystalloid or colloid continues several decades after it began. ${ }^{32}{ }^{33}$ Many recent papers advocating either group emphasise the heterogeneity within both categories of resuscitation fluid. ${ }^{34}{ }^{35}$ Resuscitation fluids should be evaluated on an individual basis and not in terms of generic groupings.

Isotonic crystalloid solutions are cheap, easy to store and to warm, and have an established safety record when they are used appropriately. They produce a relatively predictable rise in cardiac output and are generally distributed evenly throughout the extracellular space. They do not draw water out of the intravascular space. The use of Ringer's solution as the fluid of choice in burns is noted. ${ }^{36}$ It offers some buffering capacity, but carries a theoretical risk of iatrogenically increasing lactic acidosis ${ }^{37}$ in large doses or in patients with liver failure. Saline in large quantities may produce a hyperchloraemic acidosis. ${ }^{38}$ The case for hypertonic solutions in head injury has not yet been conclusively established in a randomised controlled trial. A meta-analysis by Wade et al strongly suggests a survival advantage and such a trial is urgently required..$^{39}$

At present, isotonic saline is recommended as the first line fluid in the resuscitation of a hypovolaemic trauma patient.

\section{QUANTITY OF FLUID USED IN RESUSCITATION Issues}

The dilemma that faces medical personnel confronted with a hypovolaemic trauma patient is essentially the balance between:

- administering fluid; thereby risking delay in transfer, rebleeding, and increased blood loss

and

- withholding fluid; thereby permitting the possibility organ ischaemia and death from hypovolaemia, before arrival in hospital.

This quandary is not new. Cannon's 1918 paper $^{40}$ makes it clear that he considered administration of fluids before the surgical control of bleeding to be dangerous. The same outlook governed thinking on fluid replacement in the second world war. $^{41}$

There is evidence that in penetrating torso trauma, aggressive use of intravenous fluids is detrimental to outcome. ${ }^{42}$ In a randomised controlled trial, patients received either no fluid prehospital or immediate fluid resuscitation. Reduced mortality and complications were seen if fluid resuscitation was delayed until surgery. Although methodological criticisms have been raised, ${ }^{43}$ this study remains extremely influential because it is a rare prospective, randomised study in this area. There are also animal studies that raise similar doubts about the effectiveness ${ }^{44}$ or safety ${ }^{45}$ of early fluid replacement.

Most of trauma seen in the United Kingdom is blunt trauma. Unfortunately, there is little available data from human studies regarding whether blunt trauma differs significantly from penetrating trauma in its behaviour. In a retrospective case matched review of severe trauma victims, 217 patients who had onsite fluid replacement fared worse, in terms of mortality, than controls receiving no fluid. ${ }^{46}$ Increased prehospital times and fluid administration were identified as risk factors, requiring further investigation.

Enthusiasm for aggressive fluid resuscitation during the second half of the 20th century probably had its roots in early animal haemorrhage experiments conducted by Wiggers and other workers in the 1950s and 1960s. ${ }^{47}$ In his classic model, blood was taken out through a catheter until a set pressure was reached, after which withdrawal ceased. Administration of fluid after this improved outcome. Traverso used a similar porcine model, ${ }^{48}{ }^{49}$ but this time a fixed volume was removed. The problem with both studies is that haemorrhage had ceased before resuscitation and would not recommence because of its controlled nature. In the trauma patient, there are no such guarantees.

More recently, animal experiments have attempted to replicate the possibility of uncontrolled haemorrhage more closely. There are two main groups of experiments; external haemorrhage models (for example, rat tail amputation) and internal haemorrhage models, where a controlled injury to a great vessel or major abdominal artery produces hypovolaemia. Overall, the external haemorrhage models suggest that bleeding and mortality will increase if fluid is administered before haemostasis. ${ }^{450-52}$ Some authors, however, found improved survival in resuscitated rats, although Sindlinger noted increased blood loss. ${ }^{53}$ Soucy identified anaesthetic agents as an important confounding factor and there are many methodological arguments, which make extrapolation to human trauma difficult. ${ }^{545}$ Internal haemorrhage experiments on rats and pigs seem to provide clearer evidence that aggressive fluid administration reduces survival. ${ }^{17}$ 56-58

Many of the ways in which fluid may worsen bleeding have been outlined already. Bickell discusses these mechanisms in some detail. ${ }^{17} \mathrm{He}$ suggests that an important danger in penetrating large vessel injury is that the improvement in haemodynamics brought about by administration of fluid will cause primary extraluminal thrombus to be dislodged. Using a porcine aortotomy model, he confirmed that aggressive replacement of blood loss with three times the volume of crystalloid increased haemorrhage and decreased survival.

Attention has therefore become focused on resuscitation strategies. Stern and Kowalenko bled pigs rapidly through a femoral catheter then produced an aortotomy using steel wire. Animals haemorrhaged down to a pulse pressure of $5 \mathrm{~mm} \mathrm{Hg}$. They were then resuscitated to a systolic pressure of 40,60 , or $80 \mathrm{~mm} \mathrm{Hg}$. The most bleeding and the highest mortality were seen in the $80 \mathrm{~mm} \mathrm{Hg}$ group. The $60 \mathrm{~mm} \mathrm{Hg}$ group were less acidotic than the $40 \mathrm{~mm} \mathrm{Hg}$ group. Riddez ${ }^{59}$ performed a standardised aortotomy in dogs. There were four resuscitation groups; no fluid, 1:1 volume ratio Ringer's, 2:1 Ringer's, and 3:1 Ringer's replacement. Aortic blood flow increased with the amount of fluid used. Blood loss also increased. The highest mortality was seen in the no fluid and the 3:1 groups. The authors felt that the deaths in the less aggressive fluid replacement groups were attributable to shock and those in the more vigorously resuscitated dogs were attributable to re-bleeding. Similar findings in rats were noted by Capone and Kim. ${ }^{52}{ }^{60}$ These findings seem to suggest that the best strategy is not to withhold fluid altogether, but that a moderate replacement policy is likely to be most successful.

Permissive hypotension describes the approach in which the blood pressure is allowed to remain below the normal levels seen in health, with the aim of maintaining vital organ perfusion without exacerbating haemorrhage. A review of hypotensive resuscitation is provided by Hyde. ${ }^{6}$

If hypotensive resuscitation is the best paradigm, the problem will be translating its use practically into the field. One prescription will not be suitable for all trauma victims. It is also vital that in the prehospital phase of patient care, strategies are straightforward, reflecting the difficulties of treating trauma victims on scene and in transit, without detailed diagnostic information. One method to minimise the risk of excessive fluid administration is to give small boluses of fluid at a time. The number of these could even be limited unless authorisation was sought by means of a call to a control centre. The $250 \mathrm{ml}$ boluses are easy to administer from $500 \mathrm{ml}$ or 1 litre bags.

Protocols can be based around easily available physiological measures. The presence or absence of a radial pulse gives an approximate guide to whether the blood pressure is above or below $80-90 \mathrm{~mm} \mathrm{Hg}$. Brachial pulse corresponds to about $70-80 \mathrm{~mm} \mathrm{Hg}$ and a central (femoral or carotid) to $60-70 \mathrm{~mm}$ Hg. ${ }^{62}$ Deakin has recently criticised these figures. ${ }^{63-65}$ It is 
known that a degree of hypotension in trauma can be tolerated and that this tolerance is linked to physiological compensation mechanisms, especially to haemostasis. Differing limits on the degree of hypotension that should be permitted can be found. ${ }^{66}$ However, it is probable that subgroups tolerate hypotension differently. The patient with a head injury may require a higher pressure to maintain cerebral perfusion and reduce secondary brain injury. ${ }^{68}$ Patients with penetrating torso trauma probably require lower pressures. The elderly population are known to tolerate hypotension badly. However, no evidence has been found so far that that these patients should receive qualitatively different treatment from the population at large.

\section{Consensus view}

Fluid should not be administered to trauma victims before haemorrhage control if a radial pulse can be felt. Judicious aliquots of $250 \mathrm{ml}$ should be titrated for other patients. If the radial pulse returns, fluid resuscitation can be suspended for the present and the situation monitored. In penetrating torso trauma the presence of a central pulse should be considered adequate. In children less than 1 year old, the use of a brachial pulse is more practical as it is easier to feel.

\section{SUMMARY}

Fluid administration for trauma in the prehospital environment is a challenging and controversial area. There is not yet any equivocal answer that can be supported by clear unanswerable evidence. Nevertheless, a careful reading of what evidence is available does permit some provisional conclusions to be drawn. We believe that the following represent the best possible current expert consensus on prehospital fluids in trauma. As future evidence brings clarity to this area, these guidelines can be modified, and further consensus statements will be issued taking into account such information.

When treating trauma victims in the prehospital arena:

- Cannulation should take place en route where possible

- Only two attempts at cannulation should be made

- Transfer should not be delayed by attempts to obtain intravenous access

- Entrapped patients require cannulation at the scene

- Normal saline is recommended as a suitable fluid for administration to trauma patients

- Boluses of $250 \mathrm{ml}$ fluid may be titrated against the presence or absence of a radial pulse (caveats; penetrating torso injury, head injury, infants)

\section{List of participants}

Brian Steggles, Keith Porter, Philip Munrow, Andrew Thurgood, Tim Hodgetts, Ian Greaves, Lee Turner, Ian Robertson-Steel, Mark Gough, John McDonald, Keith Allison, Tim Coates, Mark Turner, Janette Turner, Matthew Revell, Professor Ann-Marie Kelly (Professor of Emergency Medicine in Melbourne).

\section{Groups represented}

Faulty of Pre-hospital Care \& Faculty of Accident \& Emergency Medicine, Royal College of Surgeons of Edinburgh; The United Kingdom Military Defence Forces; Ambulance Service Association with Paramedics representatives; British Association for Immediate Care (BASICS); London Helicopter Emergency Medical Service (HEMS); Researchers with an interest in prehospital care.

\section{Contributors}

The consensus meeting was initailly conceived by the Faculty of PreHospital Care of the Royal College of Surgeons of Edinburgh. The meeting was arranged by Mr Keith Porter and Mr Andrew Thurgood. The principal presentations at the meeting regarding the current evidence base were by Mr Matthew Revell and debate was led by Mr Porter as consensus statements were reached. After the meeting, provisional comments were invited by email before a document was drawn up. Mr Revell's preliminary draft was subsequently revised and edited by Mr Porter and Mr Greaves.

\section{Authors' affiliations}

M Revell, Specialist Registrar, Trauma and Orthopaedics, Birmingham, West Midlands, UK

K Porter, Department of Trauma and Orthopaedics, Selly Oak Hospital, Birmingham, UK

I Greaves, Department of Accident and Emergency Medicine,

Peterborough District Hospital, Peterborough,UK

\section{REFERENCES}

1 American College of Physicians. Purpose and procedure. Evidence-based medicine. London: BM Publishing, 1998:34-5.

2 American College of Surgeons Committee on Trauma. ATLS Advanced trauma life support for doctors. Chicago: American College of Surgeons Committee on Trauma, 1997.

3 Pons PT, Moore EE, Cusick JM, et al. Prehospital venous access in an urban paramedic system-a prospective on-scene analysis. J Trauma Injury Infect Crit Care 1988;28:1460-3.

4 Mahoney P, Haii-Michael PJ. Therapeutics. In: Greaves I, Porter KM, ed. Pre-hospital medicine. London: Arnold, 1999:167-77.

5 Wears RL, Winton CN. Load and go versus stay and play: analysis of prehospital fluids therapy by computer simulation. Ann Emerg Med 1990;19:163.

6 Demetriades D, Chan L, Cornwell E, et al. Paramedic vs private transportation of trauma patients. Effect on outcome. Arch Surg 1996;131:133-8

7 Jacobs LM, Sinclair A, Beiser A, et al. Prehospital advanced life support benefits in trauma. J Trauma Injury Infect Crit Care 1984;24:8-13.

8 Pepe PE, Wyatt $\mathrm{CH}$, Bickell WH, et al. The relationship between total prehospital time and outcome in hypotensive victims of penetrating injuries. Ann Emerg Med 1987;16:293-7.

9 Powar M, Nguyen-Van-Tam J, Pearson J, et al. Hidden impact of paramedic interventions. J Accid Emerg Med 1996;13:383-5.

10 Nicholl J, Hughes S, Dixon S, et al. The costs and benefits of paramedic skills in pre-hospital trauma care. Health Technol Assess 1998;2:i-iv $1-72$.

11 Johnson GS, Guly HR. The effect of pre-hospital administration of intravenous nalbuphine on on-scene times. J Accid Emerg Med $1995 ; 12: 20-2$.

12 Joint Royal Colleges Ambulance Service Liaison Committee. Guidelines for cannulation.

13 O'Gorman M, Trabulsy P, Pilcher DB. Zero-time prehospital i.v. J Trauma Injury Infect Crit Care 1989;29:84-6.

14 Slovis CM, Herr EW, Londorf D, et al. Success rates for initiation of intravenous therapy en-route by pre-hospital care providers. Am J Emerg Med 1990;8:305-7.

15 Scott J. Immobilisation and extrication. In: Greaves I, Porter KM, eds. Pre-hospital medicine. London: Arnold, 1999:634-5.

16 Wilmink AB, Samra GS, Watson LM, et al. Vehicle entrapment rescue and pre-hospital trauma care. Injury 1996;27:21-5.

17 Bickell WH, Bruttig SP, Millnamow GA, et al. The detrimental effects of intravenous crystalloid after aortotomy in swine. Surgery $1991 ; 110: 529-36$

18 Dries DJ. Hypotensive resuscitation. Shock 1996;6:311-16.

19 Franz A, Braunlich P, Gamsjager T, et al. The effects of hydroxyethy starches of varying molecular weights on platelet function. Anesth Analg 2001;92: 1402-7.

20 Ferrara A, MacArthur JD, Wright HK, et al. Hypothermia and acidosis worsen coagulopathy in the patient requiring massive transfusion. Am J Surg 1990;160:515-18.

21 Watts DD, Trask A, Soeken K, et al. Hypothermic coagulopathy in trauma: effect of varying levels of hypothermia on enzyme speed, platelet function, and fibrinolytic activity. J Trauma Injury Infect Crit Care 1998:44:846-54.

22 Traverso LW, Medina F, Bolin RB. The buffering capacity of crystalloid and colloid resuscitation solutions. Resuscitation 1985;12:265-70.

23 Zakria B, Bascom J. Mechanisms of multiple organ failure. In: Zakria B, $\mathrm{Oz}$ M, Carlson R, eds. Reperfusion injuries and clinical capillary leak syndrome. New York: Futura, 1994:443-92.

24 Traylor R, Pearl R. Crystalloid vs colloid. Anesth Analg 1996;83:443-92

25 Sutcliffe A. Crystalloids and colloids for volume replacement. Trauma 1999;1:115-23.

26 Watts J, Gosling P, Makin A, et al. Fluid resuscitation with colloid or crystalloid solutions. BM 1998;317:277.

27 Gosling P. Albumin: friend or foe? Trauma 2000;2: 125-34.

28 Boldt J, Heesen $M$, Padberg $W$, et al. The influence of volume therapy and pentoxifylline infusion on circulating adhesion molecules in trauma patients. Anaesthesia 1996:51:529-35.

29 Liunstrom K. Colloid safety: fact and fiction. Ballieres Clin Anaesthesiol 1997; 11:163-77

30 Cohn SM. Is blood obsolete? J Trauma 1997;42:730-2.

31 Conhaim RL, Harms BA. Hemoglobin therapeutics in hemorrhagic shock. Current Opinion in Critical Care 1998:4:442-6.

32 Schierhout G, Roberts I. Fluid resuscitation with colloid or crystalloid solutions in critically ill patients: a systematic review of randomised trials. BM 1998;316:961-4.

33 Alderson P, Schierhout G, Roberts I, et al. Colloids versus crystalloids for fluid resuscitation in critically ill patients. Cochrane Database of Systematic Reviews (computer file) 2000:CD000567. 
34 Bunn F, Alderson P, Hawkins V. Colloid solutions for fluid resuscitation. Cochrane Database of Systematic Reviews (computer file) 2000):CD001319

35 Choi PT, Yip G, Quinonez LG, et al. Crystalloids vs. colloids in fluid resuscitation: a systematic review. Crit Care Med 1999;27:200-10.

36 Shirani KZ, Vaughan GM, Mason AD Jr, et al. Update on current therapeutic approaches in burns. Shock 1996;5:4-16.

37 Veech RL. Immediate versus delayed fluid resuscitation in patients with trauma. N Engl J Med 1995;332:681-2, 682-3.

38 Williams EL, Hildebrand KL, McCormick SA et al. The effect of intravenous lactated Ringer's solution versus $0.9 \%$ sodium chloride solution on serum osmolality in human volunteers. Anesth Analg 1999;88:999-1003

39 Wade CE, Grady JJ, Kramer GC, et al. Individual patient cohort analysis of the efficacy of hypertonic saline/dextran in patients with traumatic brain injury and hypotension. J Trauma Injury Infect Crit Care 1997;42 (suppl 5):S61-5.

40 Cannon W, Fraser J, Cowell E. The preventative treatment of wound shock. JAMA 1918;618-21.

41 Office of the Surgeon General. Surgery in world war II. General surgery. Washington: US Government Printing Office, 1952.

42 Bickell WH, Wall W Jr, Pepe PE, et al. Immediate versus delayed fluid resuscitation for hypotensive patients with penetrating torso injuries. $N$ Engl J Med 1994;331:1105-9.

43 Various authors. Immediate versus delayed fluid resuscitation in patients with trauma. [Correspondence]. N Engl J Med 1995;332:681-3.

44 Chudnofsky CR, Dronen SC, Syverud SA, et al. Early versus late fluid resuscitation: lack of effect in porcine hemorrhagic shock. Ann Emerg Med 1989;18:122-6.

45 Krausz MM, Landau EH, Klin B, et al. Hypertonic saline treatment of uncontrolled hemorrhagic shock at different periods from bleeding. Arch Surg 1992;127:93-6

46 Sampalis JS, Tamim H, Denis R, et al. Ineffectiveness of on-site intravenous lines: is prehospital time the culprit? J Trauma Injury Infect Crit Care 1997:43:608-15, 615-17.

47 Wiggers CJ. Experimental hemorrhage shock. In: Physiology of shock. New York: The Commonwealth Fund, 1950:121-43

48 Traverso LW, Lee WP, Langford M. Fluid resuscitation after an otherwise fatal hemorrhage: I. Crystalloid solutions. J Trauma Injury Infect Crit Care 1986;26:168-75.

49 Traverso LW, Hollenbach SJ, Bolin RB, et al. Fluid resuscitation after an otherwise fatal hemorrhage: II. Colloid solutions. J Trauma Injury Infect Crit Care 1986;26:176-82.

50 Krausz MM, Bar-Ziv M, Rabinovici R, et al. "Scoop and run" or stabilize hemorrhagic shock with normal saline or small-volume hypertonic saline? J Trauma Injury Infect Crit Care 1992;33:6-10.

51 Rabinovici R, Krausz MM, Feuerstein G. Control of bleeding is essential for a successful treatment of hemorrhagic shock with 7.5 per cent sodium chloride solution. Surg Gynecol Obstetr 1991;173:98-106.
52 Capone A Safar P, Stezoski SW et al. Uncontrolled hemorrhagic shock outcome model in rats. Resuscitation 1995;29:143-52.

53 Sindlinger JF, Soucy DM, Greene SP, et al. The effects of isotonic saline volume resuscitation in uncontrolled hemorrhage. Surg Gynecol Obstetr 1993; 177:545-50

54 Soucy DM, Sindlinger JF, Greene SP, et al. Effects of anesthesia on a model of uncontrolled hemorrhage in rats. Crit Care Med 1995:23: 1528-32.

55 Soucy DM, Sindlinger JF, Greene SP, et al. Isotonic saline resuscitation in uncontrolled hemorrhage under various anesthetic conditions. Ann Surg 1995;222:87-93.

56 Bickell WH, Bruttig SP, Millnamow GA, et al. Use of hypertonic saline/dextran versus lactated Ringer's solution as a resuscitation fluid after uncontrolled aortic hemorrhage in anesthetized swine. Ann Emerg Med 1992;21:1077-85.

57 Craig RL, Poole GV. Resuscitation in uncontrolled hemorrhage. Am Surg 1994;60:59-62.

58 Stern SA, Dronen SC, Wang X. Multiple resuscitation regimens in a near-fatal porcine aortic injury hemorrhage model. Acad Emerg Med 1995;2:89-97.

59 Riddez L, Johnson L, Hahn RG. Central and regional hemodynamics during crystalloid fluid therapy after uncontrolled intra-abdominal bleeding. J Trauma Injury Infect Crit Care 1998;44:433-9

$60 \mathrm{Kim}$ SH, Stezoski SW, Safar P, et al. Hypothermia and minimal fluid resuscitation increase survival after uncontrolled hemorrhagic shock in rats. J Trauma Injury Infect Crit Care 1997;42:213-22.

61 Hyde JAJ, Rooney SJ, Graham TR. Hypotensive resuscitation. Trauma 1998;177-85.

62 Anonymous. Shock. In: Greaves I, Porter KM, Ryan JM, eds. Trauma care manual. London: Arnold, 2000:71-86.

63 Deakin CD, Low JL. Accuracy of the advanced trauma life support guidelines for predicting systolic blood pressure using carotid, femoral, and radial pulses: observational study. BM 2000;321:673-4.

64 Russell IS. Accuracy of ATLS guidelines for predicting systolic blood pressure: Authors' core assertion was wrong. BM 2001;322:552.

65 Deakin CD. Accuracy of ATLS guidelines for predicting systolic blood pressure: Authors' reply. BM 2001;322:552

66 Stern SA, Dronen SC, Birrer P, et al. Effect of blood presure on haemorrhage volume and survival in near-fatal haemorrhage model incorporating a vascular injury. Ann Emerg Med 1993;22:155-63.

67 Bock BF, Berk WA, Bonner SC, et al. Pre-hospital medical care of the injured patient. In: Wilson RF, Walt AJ, eds. Management of trauma: piffalls and practice. 2nd edn. New York: Williams and Wilkins, 1996:8-9.

68 Miller JD, Becker DP. Secondary insults to the injured brain. J R Coll Surg Edinb 1982;27:292-8. 